\title{
A CLINICAL TRIAL TO STUDY OUTCOME IN PATIENTS OF CENTRAL SEROUS CHORIORETINOPATHY BY IDENTIFICATION AND MANAGEMENT OF RISK FACTORS
}

Priyanka Jain1, Shikha Agarwal2, Anurag Agrawal ${ }^{3}$

${ }^{1}$ Assistant Professor, Department of Ophthalmology, Mulayam Singh Yadav Medical College, Meerut, Uttar Pradesh, India.

${ }^{2}$ Assistant Professor, Department of Ophthalmology, Career Institute of Medical Sciences, Lucknow, Uttar Pradesh, India.

${ }^{3}$ Associate Professor, Department of Psychiatry, Career Institute of Medical Sciences, Lucknow, Uttar Pradesh, India.

\section{ABSTRACT}

\section{BACKGROUND}

Central serous chorioretinopathy (CSCR) is a benign idiopathic disorder of the outer blood retinal barrier seen predominantly in otherwise healthy young males \& middle-aged men (20-50 years). Stressful life and intake of steroids are major associated factors for developing CSCR. Other associated factors include gastritis, ulcer problems specially $H$. pylori induced ulceration, type A personality, history of OCP's [oral contraceptive pills] intake, abnormal sleep pattern. There is no definite treatment for this disease till now. We want to evaluate the risk factors and treatment options to improve outcome in terms of duration as well as vision.

\section{METHODS}

A prospective interventional clinical trial was carried out on 20 eyes of 20 patients of "central serous chorioretinopathy" and divided the patients into 3 groups according to associated risk factors. Group A- $(n=10)$ in case no associated factor or with type A personality treated with nepafenac eye drop only with life style counselling. Group B (n=06) if anxiety present- nepafenac with anxiolytic drugs like tab alprazolam $0.25 \mathrm{mg}$ at bed time. Group C $(\mathrm{n}=04)$ if gastritis found -nepafenac with anti $H$. pylori treatment.

\section{RESULTS}

In group B and group C $100 \%$ patient improved in 3 months and in group A in $60 \%$ patients improvement is seen in 3 months and in $80 \%$ patients improvement is seen in 6 months.

\section{CONCLUSIONS}

On observation under medical treatment, with specific treatment in the form of topical nepafenac (eye drops) along with the treatment given for the associated factors to those who had any of the associated factors of CSCR in them, it was seen that almost (90-100\%) cases showed complete improvement in visual acuity and clinical features (viz micropsia, macropsia, photopsia) in a time span of 3-6 months.

\section{KEY WORDS}

Anxiety, Type A Personality, Gastritis, Risk Factor

HOW TO CITE THIS ARTICLE: Jain P, Agarwal S, Agrawal A. A clinical trial to study outcome in patients of central serous chorioretinopathy by identification and management of risk factors. J. Evolution Med. Dent. Sci. 2019;8(28):2251-2254, DOI: $10.14260 /$ jemds/2019/493

\section{BACKGROUND}

Central serous chorioretinopathy (CSCR) is a benign idiopathic disorder of the outer blood retinal barrier, characterized by the presence of serous sensory retinal detachment with an active retinal pigment epithelium leakage without any evidence of ocular or systemic disorder known to produce a similar presentation.(1) Retinalpigmented epithelium (RPE) functions as a pump that maintains a fine RPE-photoreceptor adhesion and a dry sub retinal space. It also acts as a barrier to the physiological leakage from choriocapillaris.

'Financial or Other Competing Interest': None.

Submission 13-05-2019, Peer Review 26-06-2019,

Acceptance 05-07-2019, Published 15-07-2019.

Corresponding Author:

Dr. Shikha Agarwal,

10/403, Malhar Deluxe,

Sahara Grace Apartment,

Jankipuram, Lucknow-226021,

Uttar Pradesh, India.

E-mail: shikha.agarwal.dp@gmail.com

DOI: $10.14260 /$ jemds $/ 2019 / 493$
In CSCR due to unknown reason, there is breakdown (physiological breakdown -no anatomical discontinuity) of this barrier which leads to plasma leakage from the affected RPE, which manifest as the leakage point on FFA into the sub retinal space.

The condition is seen predominantly in otherwise young males \& middle-aged men (20-50 years) with a male to female ratio of 10:1(2) with no previous medical and family history and no systemic symptom or signs.(3) The usual presenting symptoms are blurred vision, metamorphopsia, micropsia, a relative positive scotoma and occasional macropsia.

Visual acuity ranges from $20 / 20(6 / 6)$ to $20 / 200(6 / 60)$, but it is most commonly $20 / 40(6 / 12)$ or better. There may be a delay in retinal recovery time after exposure to bright light, loss of colour sensation and loss of contrast sensitivity. Visual acuity (VA) is often moderately decreased, which might be improved with the addition of small hyperopic correction. The patient might be asymptomatic if the serous detachment does not extend into the center of macula. In most of cases CSCR is self-limited and resolve spontaneously in 4-6 month with mild colour and contrast sensitivity alteration. The final visual acuity is generally excellent with 
90-100\% of patients achieving of final acuity of better than or equal to $20 / 40^{(1)}$. Severe visual loss is however, reported in $5 \%$ of patients affected with CSCR. The condition is bilateral in up to $30 \%$ of cases and recurrence occurs in about one third to one half of patients. The diagnosis is confirmed by fluorescein angiography and indocyanine green angiography, which reveal the site of serous fluid leakage from RPE into the sub retinal space and identify choroidal hyper permeability and ischemia.

Exact aetiology of CSCR is not known, but it may be mechanical, infective, vasomotor, toxic, psychosomatic etc. Stressful life and intake of steroids are major associated factors for developing CSCR. Other associated factors includes-gastritis, ulcer problems specially $H$. pylori induced ulceration, type a personality, history of OCP's intake, abnormal sleep pattern.(4) H. pylori gastric infection has been implicated as an important factor in occlusive arterial pathology. It is suspected that CSCR is due to a multifocal vascular occlusive disease of choriocapillaris. There is no definite treatment for this disease till now, in this study we identified risk factors and treated accordingly to improve outcome in terms of duration as well as vision.

Various Treatment modalities available for CSCR are selflimiting, observation, reassurance, withdrawal of exogenous corticosteroids, treatment of the associated conditions such as $H$. pylori infection, obstructive sleep apnoea syndrome, Vitamin preparations, tranquilizers, antituberculosis medication, anti-allergic, non-steroidal Anti-inflammatory, Catecholamines given in associated condition of stress and type A personality disorder also plays an important role. Beta-blockers have also been explored for treatment of CSCR with conflicting result. Acetazolamide treatment for CSCR has been shown to shorten the time for subjective and objective clinical resolution but has had no effect on either final VA or recurrence rate of disease. Laser treatment for the management of CSCR remains a controversial issue, because of favourable visual outcome commonly observed after spontaneous disease remission. A possible mechanism for laser treatment is debridement of disease RPE permitting in growth of surrounding healthy RPE and resolution of CSCR. Safe and effective laser treatment achieved only limited result in the management of chronic, severe, or recurrent CSCR that were associated with persistent subretinal fluid and central RPE atrophy.

\section{METHODS}

Written informed consent was taken from all the patients after giving them a full description of the study and study was approved by the IEC.

A prospective interventional clinical trial carried out on patients of "central serous chorioretinopathy" who attended the OPD of department of ophthalmology, Mulayam Singh Yadav Medical College, Meerut, U. P., during the period March -2016 to January- 2018. Total 26 eyes [26 patients] were screened and out of that 20 eyes [20 patients] were included in study. 06 eyes [06 patients] excluded due to associated ocular diseases [history of ocular trauma, previous attack of CSCR, corneal opacity].

\begin{tabular}{|c|c|c|}
\hline Category & $\begin{array}{c}\text { Associated Risk } \\
\text { Factor }\end{array}$ & Treatment Given \\
\hline $\begin{array}{c}\text { Group A } \\
\text { (n= 10) }\end{array}$ & $\begin{array}{c}\text { No associated factor or } \\
\text { with type A personality }\end{array}$ & $\begin{array}{c}\text { Treated with nepafenac eye drop only with } \\
\text { life style counseling. No other specific } \\
\text { medications were given }\end{array}$ \\
\hline $\begin{array}{c}\text { Group B } \\
\text { (n= 06) }\end{array}$ & anxiety present & $\begin{array}{c}\text { Nepafenac with anxiolytic drugs. } \\
\text { Tranquilizers like tab alprazolam } 0.25 \mathrm{mg} \\
\text { at bed time }\end{array}$ \\
\hline $\begin{array}{c}\text { Group C } \\
\text { (n= 04) }\end{array}$ & Gastritis found & Nepafenac with anti $H$. pylori treatment * \\
\hline \multicolumn{2}{|c|}{ Table 1. Category According to Risk Factors and Treatment Given } \\
\hline * (H-PYLORI KIT $\rightarrow$ omeprazole $\rightarrow 20 \mathrm{mg} \times$ od, clarithromycin $\rightarrow 250 \mathrm{mg} \times$ tds, \\
tinidazole $\rightarrow 500 \mathrm{mg} \times$ bd, for a period of $3-4$ weeks).
\end{tabular}

\begin{tabular}{|c|c|c|}
\hline Associated Factors & No. of Patients & \begin{tabular}{|l|} 
Percentage (\%) \\
\end{tabular} \\
\hline History of Stress & 06 & 30.0 \\
\hline History of Gastritis & 04 & 20.0 \\
\hline History of Abnormal Sleep Pattern & 00 & 00.0 \\
\hline Type-A Personality & 02 & 10.0 \\
\hline History of OCP's Intake & 00 & 00.0 \\
\hline History of Oral Steroids Intake & 00 & 00.0 \\
\hline No cause & 08 & 40.0 \\
\hline Total & 20 & 100.0 \\
\hline
\end{tabular}

\begin{tabular}{|c|c|c|c|c|c|c|c|c|c|}
\hline \multirow{2}{*}{$\begin{array}{c}\text { Visual } \\
\text { Acuity }\end{array}$} & \multicolumn{2}{|c|}{$\begin{array}{c}\text { Group a (No. of } \\
\text { Patient) (Total 10) }\end{array}$} & \multicolumn{2}{c|}{$\begin{array}{c}\text { Group b (No. of } \\
\text { Patient) (Total 06) }\end{array}$} & \multicolumn{2}{c|}{$\begin{array}{c}\text { Group c (No. of } \\
\text { Patient) (Total 04) }\end{array}$} \\
\cline { 2 - 10 } & $\begin{array}{c}\text { 1st } \\
\text { Month }\end{array}$ & $\begin{array}{c}\text { 3rd } \\
\text { Month }\end{array}$ & $\begin{array}{c}\text { 6th } \\
\text { Month }\end{array}$ & $\begin{array}{c}\text { 1st } \\
\text { Month }\end{array}$ & $\begin{array}{c}\text { 3rd } \\
\text { Month }\end{array}$ & $\begin{array}{c}\text { 6th } \\
\text { Month }\end{array}$ & $\begin{array}{c}\text { 1st } \\
\text { Month }\end{array}$ & $\begin{array}{c}\text { 3rd } \\
\text { Month }\end{array}$ & $\begin{array}{c}\text { 6th } \\
\text { Month }\end{array}$ \\
\hline Improved & 02 & 06 & 08 & 02 & 06 & 06 & 00 & 04 & 04 \\
\hline Unchanged & 8 & 04 & 00 & 04 & 00 & 00 & 04 & 00 & 00 \\
\hline Worse & 0 & 00 & 02 & 00 & 00 & 00 & 00 & 00 & 00 \\
\hline \multicolumn{10}{|c|}{ Table 3. Change in Visual Acuity in Follow-Up } \\
\hline
\end{tabular}

\begin{tabular}{|c|c|c|c|c|c|c|c|c|c|}
\hline \multirow{2}{*}{$\begin{array}{c}\text { Clinical } \\
\text { signs }\end{array}$} & $\begin{array}{c}\text { Group a (No. of } \\
\text { Patient) (Total 10) }\end{array}$ & \multicolumn{2}{c|}{$\begin{array}{c}\text { Group b (No. of } \\
\text { Patient) (Total 06) }\end{array}$} & \multicolumn{2}{c|}{$\begin{array}{c}\text { Group c (No. of } \\
\text { Patient) (Total 04) }\end{array}$} \\
\cline { 2 - 10 } & $\begin{array}{c}\text { 1st } \\
\text { Month }\end{array}$ & $\begin{array}{c}\text { 3rd } \\
\text { Month }\end{array}$ & $\begin{array}{c}\text { 6th } \\
\text { Month }\end{array}$ & $\begin{array}{c}\text { 1st } \\
\text { Month }\end{array}$ & $\begin{array}{c}\text { 3rd } \\
\text { Month }\end{array}$ & $\begin{array}{c}\text { 6th } \\
\text { Month }\end{array}$ & $\begin{array}{c}\text { 1st } \\
\text { Month }\end{array}$ & $\begin{array}{c}\text { 3rd } \\
\text { Month }\end{array}$ & $\begin{array}{c}\text { 6th } \\
\text { Month }\end{array}$ \\
\hline Improved & 05 & 04 & 08 & 02 & 06 & 06 & 00 & 02 & 04 \\
\hline Jnchanged & 05 & 06 & 00 & 04 & 00 & 00 & 04 & 02 & 00 \\
\hline Worse & 00 & 00 & 02 & 00 & 00 & 00 & 00 & 00 & 00 \\
\hline \multicolumn{8}{|c|}{ Table 4. Change in Clinical Signs in Follow-Up } \\
\hline
\end{tabular}

\section{History}

Demographic data, time and mode of onset of disease, history of black spot in front of eye[s], metamorphopsia or micropsia, progression of disease, history of various known associated factors for the disease like stress, type A personality, history of gastric acidity/ulceration, any drug intake like steroids or oral contraceptives, other associated systemic disease like cardiovascular, respiratory, central nervous and renal system.

\section{Examination}

Visual acuity - UCVA AND BCVA, slit lamp examination, macular function test using Amsler grid, colour vision, contrast sensitivity, photo stress test, Fundus examination in dilatated pupil.

\section{Positive Findings on Fundus Examination in CSCR}

- Loss of foveal reflex on direct ophthalmoscopy.

- Well circumscribed and elevated central retina with subretinal fluid collection in fresh cases.

- Macular scarring, RPE changes or turbid fluid collection depending upon the duration and recurrence of disease.

\section{Investigations}

OCT, FFA AND/OR ICG. 
We identified associated risk factor by referring patients to psychiatrist for personality/ anxiety assessment and to physician for establishing diagnosis of $H$. pylori gastritis/gastric ulceration, other associated systemic disease like cardiovascular, respiratory, central nervous and renal system. The study sample was divided into following three groups according to associated risk factor and what type of treatment was required for the management of that particular risk factor. Statistical analysis done with the help of SPSS 21 software.

\section{RESULTS}

Most of the cases (60\%) were in age group of "between 30-40 year". The mean age was 34 year. Majority i.e. 12 (60.0\%) patients of CSCR were in the age group of 31-40 years. No case is reported below 20 year. CSCR is rare $2(10.0 \%)$, above the age of 50. There was 9:1 male to female ratio. 2 females (out of 20 patients) belonged to $41-50$ yrs age group. CSCR in most of cases presented with unilaterally (80.0\%), in bilateral cases other eye had previous history of CSCR/ old healed CSCR or coincidental finding of FA leak. Most of the patients of CSCR had blurring of vision in the form of black spots $(80 \%)$. While $20 \%$ patient with blurring of vision only. Most of the patients of CSCR had VA [on Snellen's chart] between $6 / 9-6 / 12(70 \%)$ while $20 \%$ has $6 / 18-6 / 24 \& 10 \%$ has $6 / 36$ $6 / 60$. Most common pattern is single point ink blot leak in $50 \%$ patients, followed by single point smoke leak $30 \%$ and $20 \%$ of patients shows multiple leak.

We found $50 \%$ patients with no associated factor or WITH type a personality (Group A), 30\% (06) with anxiety (Group B) \& 20\% (04) with gastritis (Group C). (Table 2)

Visual acuity measured periodically after giving treatment and seen for improvement/ unchanged/ worsening. In group B and group C $100 \%$ patient improved in 3 months and in group $A$ in $60 \%$ patient improvement is seen in 3 months and in $80 \%$ improvement is seen in 6 months. Charting is given below (Tables 3 and 4 ).

\section{DISCUSSION}

Whilst the acute CSCR form is clinically obvious especially in middle-aged men, the clinical diagnosis in older patients is more challenging, as chronic CSCR often resembles agerelated macular degeneration (AMD) or can be complicated by choroidal neovascularization (CNV)(5). In accordance with Duke-Elder and Dobree, it seems appropriate to limit the diagnosis to patients up to age 50 , since beyond this age, it is impossible, to distinguish central serous chorioretinopathy from some form of age-related macular degeneration. CSCR diagnosis is also difficult when occurring secondarily to steroid treatments administered for other retinal diseases.(6) Recently, enhanced visualization of the choroid with spectraldomain optical coherence tomography (SD-OCT) has facilitated a more robust assessment of CSCR.

In our study diminution of visual acuity in most of the patients (70\%) was in the range of $6 / 9-6 / 12$ that was the majority of patients have only moderate loss of vision. As told in the study by Klein Ml, 1974, experience with nontreatment with CSCR, visual acuity in the acute stage of CSCR may range from $6 / 6$ to $6 / 60$ and average $6 / 18$.(7) No patient in present study having severe diminution of vision ranging of finger counting (FC) to hand movement (HM). But in previous studies few patients had severe diminution of vision and These were the group of patients that have history of recurrent attack and on fundus examination there was macular scaring and on fluorescein angiography retinal pigment epithelial atrophic track formation and staining of macula area.

CSCR is an idiopathic disorder because the aetiology is not completely understood. But certain associated factors are observed such as history of stress, history of gastritis (Acidity), type-A personality, history of abnormal sleep pattern, history of OCP's intake, history of oral steroid intake. Most common associated factor for CSCR is known till date are stressful life, history of recurrent gastritis and type-A personality.(4) Persons with CSCR have higher levels of cortisol, explain the CSCR -stress association. There is extensive evidence to the effect that corticosteroids (e.g. Cortisone) commonly used to treat inflammations, allergies, skin conditions and even certain eye conditions can trigger CSCR, aggravate it and cause relapses. Cortisol excess may damage the posterior retinal blood barrier (Both diffuse and focal impairment of RPE cells) and cause increase capillary fragility and hyperpermeability leading to leakage of fluid in sub retinal space.(6) Both diffuse and focal impairment of RPE leakage cells have been postulated to be responsible for CSCR.

In our study most of patients $(40 \%)$ had no cause. Most common associated factor was stressful life. It was found in $30 \%$ of cases. Other next associated factor was history of gastritis (Acidity) was found in (20\%) cases. Type-A personality was found in two cases. History of oral steroids or oral contraceptive pills intake was found in no patient out of 20 patients. In female use of oral contraceptive is a risk factor. Most of the patients had leakage of dye in fellow eye during fundus fluorescein angiography. They had no symptom because the leakage was in nasal region, and diagnosed accidentally.

The typical angiographic finding occurring in about 95\% of all cases of CSCR is the presence of one or more leakage point in the RPE. In the majority of these cases the dye spreads symmetrically to all sides, slowly and evenly staining the subretinal blister and give inkblot appearance. In $7 \%$ to $20 \%$ of cases the dye enters the blister through a single leakage point, but instead of spreading evenly to all sides, it first ascends (Smokestack phenomenon) and, upon arrival at the upper limit of the blister expand laterally in a mushroom or umbrella like fashion. Shimizu and Tobari, who first described this phenomenon, believe that this is caused by an osmotic pressure gradient resulting from different protein concentration in the content of the blister and in the liquid entering through the leakage point.

In the study by Steinberg RH and Miller, Transport and Membrane properties of the retinal pigmented epithelium, 1993, the number of leakage point is usually one or two. In this study, single leak point was seen in $89 \%$ cases and multiple leak were seen in $11 \%$ cases. In our study majority of the dye leakage was of single point inkblot pattern seen in $50 \%$ cases and in $30 \%$ cases there was single point smoke stack pattern leak. While $20 \%$ cases had multiple leakage points. These findings are very near to the above study.

The leakage point is located in a $1 \mathrm{~mm}$ wide, ring like zone immediately adjacent to fovea. Beyond this ring the incidence rapidly decreases, with exception of the upper nasal quadrant where leakage point up to $3 \mathrm{~mm}$ from the center of fovea. The overall incidence of the leakage points is greatest in the upper nasal quadrant $(28.7 \%)$, followed in decreasing frequency by 
the lower nasal quadrant $(18.3 \%)$, the upper temporal quadrant $(16.4 \%)$ and lower temporal quadrant $(12.8 \%)$. Less than $10 \%$ of all cases the leakage point is found in foveal area. In 18 to $30 \%$ of cases the leakage point lies in the area of papillo-macular bundle, where the incidence above the midline is almost twice as frequent as below this line. In recurrent cases, the new leakage point lies within $1 \mathrm{~mm}$ of old leakage point in $80 \%$ of eyes. Presence of the RPE tract, appear as an area of mottled hyperfluorescence due to window defect. The most common site was upper nasal quadrant $40 \%$ cases, followed by upper temporal $20 \%$ cases, lower nasal $20 \%$ cases, lower temporal $10 \%$ cases, and FAZ in $10 \%$ cases. These data were very close to the above study.

Type A individual has been described as ambitious, rigidly organized, highly status conscious, can be sensitive, excessive care for other people, are truthful, impatient, always try to help others, take on more than they can handle, want other people to get to the point, proactive, and obsessed with time management. Such personality type itself acts as a risk factor for disease and interacts synergistically with other risk factors, such as stress and gastric ulceration. Specific psychological and personality profiles have been associated with CSCR (Piskunowicz et al., 2014; Yannuzzi, 1986) but the exact link between anxiety-sensitive personalities and steroid biology has not been elucidated and the full ocular and systemic steroid hormonal profile of CSCR patients has been only partially explored (Zakir et al., 2009). More determinants should be now considered in light of recent discoveries linking stress, corticosteroids, epigenetic modifications and cardiovascular risk factors (Hunter, 2012; Reynolds, 2013).(4,8) The multifactorial concept allows that not everyone possessing the type a behaviour pattern risk factor develops CSCR because of host specificities. In this respect, the type a hypothesis for CSCR clearly states that the disorder is not caused by a solitary etiologic factor producing a specific constellation of macular manifestations. Rather, its pathogenesis is more likely related to the interrelationship between finely balanced components of a complex biopsychological system involving a person's genetic endowment, environment, and behavioural pattern. By virtue of the concept proposed, it seems appropriate to assess patients with CSCR more broadly, assimilating psychological and clinical features of the disorder in the understanding of its pathogenesis.(9) In 2 patients we found type A personality and advised life style modification along with nepafenac eye drop and found this to shorten acute phase of disease and In those 6 patients, in which we found stress as an associated factor, we gave tranquilizer- like tablet alprazolam $0.25 \mathrm{mg}$ at bed time along with nepafenac eye drop. These drugs reduce the stress level and reduce the steroid levels of body.

In those 4 cases, in which we found recurrent gastritis as an associated factor we gave anti H-pylori kit in the treatment along with nepafenac eye drop. In the study by AsensioSachez et al. showed a possible statistical association between $H$. pylori gastric infection and CSCR. In their study, the difference in the prevalence of $H$. pylori between the CSCR group $(68.75 \%)$ and the control group (30\%) was found to be statistically significant $(\mathrm{p}<0.05)$ and they regarded H. pylori infection as a risk factor in CSCR patients.(10) In our study results showed that an anti-H- pylori treatment regimen is effective in the treatment of CSCR patients and that anti- $H$. pylori treatment can provoke the faster reabsorption of subretinal fluid. Thus, upon these results, the association between $H$. pylori and CSCR became stronger than previously thought. This new finding could lead to a new therapeutic approach to CSCR.

On observation under medical treatment, with specific treatment in the form of topical nepafenac (eye drop) along with the treatment given for the associated factors to those who had any of the associated factors of CSCR in them, it was seen that almost (90\%) cases showed complete improvement in visual acuity and clinical features (viz micropsia, macropsia, photopsia) in a time span of 3-6 months.

\section{CONCLUSIONS}

In busy practice, we tend to suggest only observation in CSCR patients with little or minimal counselling with placebos but these results suggest that there should be more detailed history, examination and referral to other specialities for any of the known associated factor for targeted approach towards the risk/causating factors which in turn shortens the acute phase of the disease.

\section{REFERENCES}

[1] Nicholson B, Noble J, Forooghian F. Central serous chorioretinopathy: update on pathophysiology and treatment. Surv Ophthalmol 2013;58(2):103-26.

[2] Latha SYJ, Madhavi C, Ashokkumar M. Visual outcome of central serous retinopathy. International Journal of Research in Medical Sciences 2015;3(8):1885-8.

[3] Wang M, Munch IC, Hasler PW, et al. Central serous chorioretinopathy. Acta Ophthalmologica 2008;86(2):126-45.

[4] Daruich A, Matet A, Dirani A, et al. Central serous chorioretinopathy: recent findings and new physiopathology hypothesis. Prog Retin Eye Res 2015;48:82-118.

[5] Filho BMA, De Carlo TE, Ferrara D, et al. Association of Choroidal Neovascularization and Central Serous Chorioretinopathy with Optical Coherence Tomography Angiography. JAMA Ophthalmol 2015;133(8):899-906.

[6] Garg SP, Dada T, Talwar D, et al. Endogenous cortisol profile in patients with central serous chorioretinopathy. Br J Ophthalmol 1997;81(11):9624.

[7] Klein ML, Van Buskirk EM, Friedman E, et al. Experience with non-treatment of central serous choroidopathy. Arch Ophthalmol 1974;91(4):247-50.

[8] Spahn C, Wiek J, Burger T, et al. Psychosomatic aspects in patients with central serous chorioretinopathy. Br J Ophthalmol 2003;87(6):704-8.

[9] Yannuzzi LA. Type-A behavior and central serous chorioretinopathy. Retina 1987;7(2):111-31.

[10] Asensio-Sánchez VM, Rodríguez-Delgado B, GarciaHerrore E, et al. Central serous chorioretinopathy as an extradigestive manifestation of Helicobacter pylori gastric infection. Arch Soc Esp Oftalmol 2008;83(3):177-82. 